\title{
Correlation between socioeconomic status and different types of prosthetic modalities in Hail Region, Saudi Arabia
}

\author{
Amal Ali Shafaei* \\ Lecturer in Fixed Prosthodontics, Restorative Department, Hail University, Hail, Saudi Arabia
}

\begin{abstract}
Objective: This study aimed to correlate between socioeconomic status of patients in Saudi Arabia and different available types of prosthetic treatment modalities.

Materials and methods: The questionnaire was completed by patients. The questionnaire included 20 items that provided information regarding socioeconomic status of Saudi Arabian volunteers and information related to prostheses. Descriptive statistic was used for data correlation where appropriate.

Results: Approximately (52.1\%) of partial edentulous volunteers replacing the missing teeth (13.5\%) of them did not complete their universal education and (86.5\%) had a universal education or more compared with (47.9\%) who not replaced their missing teeth, (19.1\%) of them with high school and less. Most of volunteers (71.8\%) belonged to fixed prostheses then followed by (17.6\%) and (10.6\%) for the implant and removable prostheses, respectively. Cost of treatment was an important factor affecting on treatment options by $(45.1 \%)$ of all participants.
\end{abstract}

Conclusion: Within limitation of this study regarding the socioeconomic status of patients in relation to different types of prosthetic treatment it was found that the level of education and monthly income have affected significantly the treatment choice.

\section{Introduction}

Teeth play an important role in the maintenance of a positive selfimage [1]. The loss of teeth results in significant disabilities, which can profoundly disrupt social activities. Tooth loss is very traumatic and upsetting and is regarded as a serious life event that requires significant social and psychological readjustment $[2,3]$. It has been suggested that adverse reactions towards edentulousness as well as the individuals' feelings about dentures are important for the acceptance of the new dentures [4]. The attitude towards tooth loss is changing. Adults have greater expectations of their dental health than in the past [5]. Research has demonstrated that several non-disease factors such as attitude, behavior, dental attendance, and characteristics of the health care system play an important role in the decision to become edentulous. In addition, a significant relationship exists between the edentulous state and fiscal concerns that are usually associated with low occupational levels. It is therefore reasonable to conclude that edentulism is due to various combinations of cultural, educational background, financial, and dental disease attitudinal determinants, as well as to treatment received in the past [6]. For example, regardless of age and gender, Chinese people in the United Kingdom believe that they are susceptible to dental disease, that one should expect to lose teeth in the older age group, and that nothing can be done to prevent it [7]. Replacement of missing teeth has become one of the most important needs for patients attending clinics to restore esthetics and/or function. Many treatment modalities are available for replacing a single missing tooth; removable partial denture, fixed partial denture or dental implant. Each modality is a possible treatment option and has its own advantages and disadvantages [8]. There are several factors affecting the final treatment decision regarding the replacement of a missing tooth, these factors are case dependent. In many cases if more than one treatment option is possible, the definitive replacement depends on patient's decision/ financial status or influenced by the patient's gender, age, public awareness and patient's knowledge. Therefore, it is mandatory to understand the patient's needs and demands to determine the kind of treatment that ensures the patient's satisfaction with the dental service. In many cases the cost of the treatment is considered as a major determinant and ahead of oral health status and patient preference. Pain and dental phobia are considered as important factors as well and they might affect the patient decision not to receive treatment at all $[9,10]$. Accessibility which highlight important differences between people. For example, a particular form of prosthetic treatment may be equally available to young and old patients, but the latter may find that the effort needed to seek out that treatment is just too great [11]. Other factors like the dentists, their particular skills, their accessibility to the public and the economic realities of the community in which they practice can affect the decision in choosing the treatment in addition to the attitudes of people towards different forms of treatment. These attitudes are influenced by such matters as education, personal finance, and cultural background [12]. Treatment decisions cannot be performed depending on the basis of clinical examination or a dentist's opinion alone, but should be discussed in close consultation with patients [13]. Several options are currently available to address the challenge of restoring a single-tooth. To select the most appropriate treatment option for each patient, every case should be evaluated and all available options should

Correspondence to: Amal Ali Shafaei, Lecturer in Fixed Prosthodontics, Restorative Department, Hail University, Hail, Saudi Arabia, Tel: +966564774300; E-mail: sasamemo1400@gmail.com

Key words: socioeconomic status, prosthetic type, replacement

Received: August 20, 2016; Accepted: September 13, 2016; Published: September 16, 2016 
be reviewed [14].

This study aimed to correlate between socioeconomic status of patients in Saudi Arabia and different available types of prosthetic treatment modalities.

\section{Materials and methods}

This study involved 200 volunteers who had missing teeth and have been successfully treated and received their prosthesis at least one year before the study. The questionnaire was completed by patients. The questionnaire included 20 items that classified into two categories:

1) Socioeconomic status of patients regarding the patient's age, gender, level of education, job, monthly income, job place, smoking habits, oral hygiene measures following and dentists visiting.

2) Prosthetic information concerning a patient's prosthetic knowledge, prosthesis kind, factors affecting the choice of treatments, their reasons for replacing the missing teeth, source of information and their overall satisfaction with their current prosthesis or situation esthetically, functionally and speech efficiency.

The study protocol was approved by the Research Ethics Committee of Hail University in Hail, Saudi Arabia

\section{Data analysis}

Online questionnaire was distributed using the web interface " Google drive doc ". to avoid duplication, we need asked the volunteers to fill out a single questionnaire. In order to improve the volunteer's response rate to the survey, resent the email to remind them to submit their answers. The completed questionnaires were eventually collected from 190 dental patients.

Completed data were statistically analyzed using Statistical Package for Social Sciences (SPSS, version 20.0). descriptive statistic was used for data correlation where appropriate.

\section{Results}

Two hundred questionnaires were distributed, of which 193 were returned (response rate:96.5\%). 51 of patient's without missing teeth were excluded. Most of volunteers were females (90.2\%) while the volunteer's male was (9.8\%). Of these, approximately $14.8 \%$ of volunteers were less than 25 years' age, $80.3 \%$ were between $25-50$ years' age and the remaining (4.9\%) were more than 50 years' age.
The results showed that only (16.2\%) of all subjects in the current study did not go to university education, while subjects with university education or high education were about $(83.8 \%)$. Although higher proportion of subjects replaced their missing teeth with prostheses belongs to university education, there was no significant difference among prosthesis type categories within this group of volunteers.

Approximately monthly income of (41.5\%) of the volunteers was less than 5000 SR, while there is no significant difference between volunteers with monthly income 5000-10000 SR (28.9\%) and who have more than 10000 SR (29.6\%).

The socioeconomic status of volunteers including gender, age, educational level and monthly income in relation to different types of prostheses are shown in Table 1.

According to job field there was $(23.9 \%)$ of volunteers worked in health field, (33.1\%) in educational field, (15.5\%) in administration field, while the remaining worked in other fields.

Approximately (62.7\%) of the volunteers worked in the governmental sector, and (37.3\%) in the private sector.

The data regarding the smoking habits and oral hygiene measures were though very encouraging and satisfactory among the patients, there were just $(11.3 \%)$ of volunteers are smoking and there were $(68.3 \%)$ following the oral hygiene measure. only $(23.9 \%)$ of the volunteers had regular dental visits.

Approximately (52.1\%) of partial edentulous volunteers replacing the missing teeth $(13.5 \%)$ of them did not complete their universal education and (86.5\%) had a universal education or more compared with (47.9\%) who not replaced their missing teeth, (19.1\%) of them with high school and less (Figure 1).

Regarding awareness of the dental prosthesis types, (43.7\%) had a good knowledge about available prosthesis, compared to (56.3\%) with no sufficient knowledge. Of this category $(71.8 \%)$ belonged to fixed prostheses then followed by (17.6\%) and (10.6\%) for the implant and removable prostheses, respectively

Regarding the source of information about the available types of prosthesis most of population bring their information form their dentists $(61.3 \%)$, social media and internet was the second source (16.2\%), while the friends were $(12.7 \%)$ and the other source were (9.9\%).

Table 1.Distribution of volunteers according to relation between socioeconomic status and different types of prostheses.

\begin{tabular}{|c|c|c|c|c|c|c|c|c|}
\hline \multirow[t]{2}{*}{ Variables } & \multicolumn{2}{|c|}{ Fixed prostheses } & \multicolumn{2}{|c|}{ Removable prostheses } & \multicolumn{2}{|c|}{ Implant } & \multicolumn{2}{|c|}{ Total } \\
\hline & $(\mathrm{N})$ & $(\%)$ & $(\mathrm{N})$ & $(\%)$ & $(\mathrm{N})$ & $(\%)$ & $(\mathrm{N})$ & $(\%)$ \\
\hline \multicolumn{9}{|l|}{ Gender } \\
\hline Male & 10 & $76.9 \%$ & 1 & $7.7 \%$ & 2 & $15.4 \%$ & 13 & $100 \%$ \\
\hline female & 92 & $71.3 \%$ & 14 & $10.9 \%$ & 23 & $17.8 \%$ & 129 & $100 \%$ \\
\hline \multicolumn{9}{|l|}{ Age } \\
\hline Less than 25 years & 17 & $81.0 \%$ & 2 & $9.5 \%$ & 2 & $9.5 \%$ & 21 & $100 \%$ \\
\hline Between 25-50 years & 79 & $69.3 \%$ & 12 & $10.5 \%$ & 23 & $20.2 \%$ & 114 & $100 \%$ \\
\hline More than 50 years & 6 & $85.7 \%$ & 1 & $14.3 \%$ & 0 & 0 & 7 & $100 \%$ \\
\hline \multicolumn{9}{|l|}{ Education } \\
\hline High school or less & 16 & $66.6 \%$ & 4 & $17.4 \%$ & 3 & $13.0 \%$ & 23 & $100 \%$ \\
\hline More than high school & 86 & $72.3 \%$ & 11 & $9.2 \%$ & 22 & $18.5 \%$ & 119 & $100 \%$ \\
\hline \multicolumn{9}{|l|}{ Monthly income } \\
\hline Less than 5000 SR & 42 & $71.2 \%$ & 8 & $13.6 \%$ & 9 & $15.3 \%$ & 59 & $100 \%$ \\
\hline Between 5000-10000 SR & 32 & $78.0 \%$ & 4 & $9.8 \%$ & 5 & $12.2 \%$ & 41 & $100 \%$ \\
\hline More than $10000 \mathrm{SR}$ & 28 & $66.7 \%$ & 3 & $7.1 \%$ & 11 & $26.2 \%$ & 42 & $100 \%$ \\
\hline
\end{tabular}


Reasons for replacing the missing teeth in the patients of this study were $(23.2 \%)$ for esthetical reasons, $(14.1 \%)$ for functional reasons and (26.1\%) of patients replaced missing teeth just to fill the space of the tooth loss, while the most of patients (35.2\%) replaced their missing teeth to preserve their good oral hygiene.

Regarding the factors that affected treatment choice, time and treatment duration was one of the most important factors when choosing between different prosthesis types (22.5\%) followed by phobia (14.1\%) and pain (12.7\%), while cost of treatment was an important factor by $(45.1 \%)$ of all participants, and only $(8 \%)$ have a problem with surgical treatment as shown in Table 2.

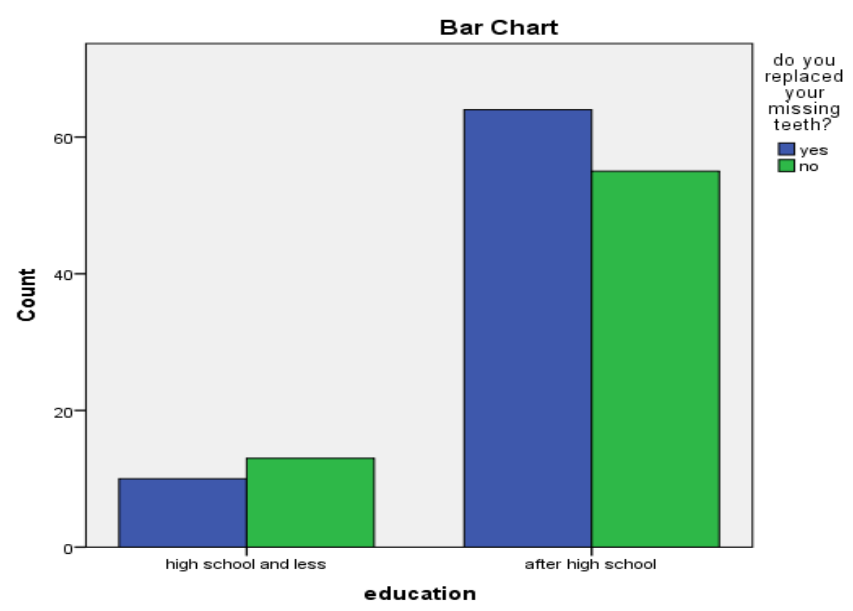

Figure 1. Relation between education level number of patients who replacing their missing teeth.

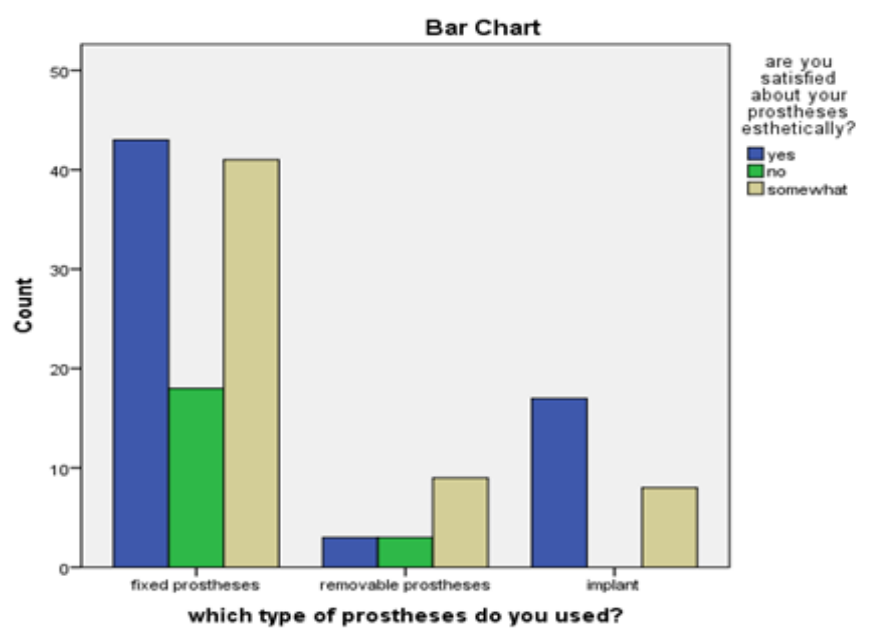

Figure 2. Patients satisfaction esthetically.
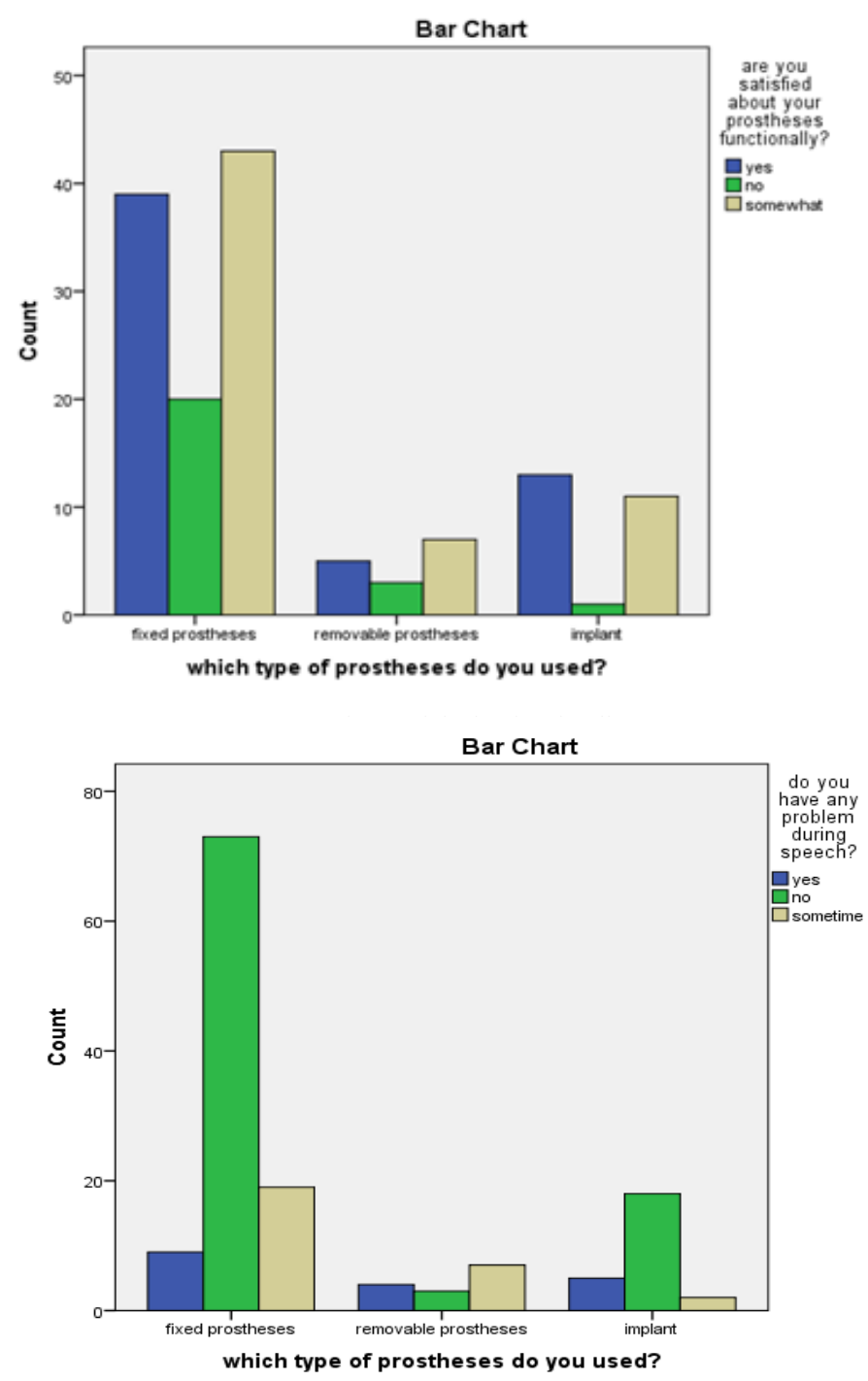

Figure 4. Speech efficiency regarding prostheses types.

Patients' satisfaction with their current prosthesis esthetically and functionally is shown in Figures 2 and 3.

According to problems during speech, (67.1\%) of patients didn't have any problem, and (20\%) of them said sometimes I have a little problem, while the rest have problems on speech with their prostheses. Most of them belongs removable prostheses (Figure 4).

Finally, when we asked the volunteers about if $\mathrm{u}$ have a choice will you re-choose your current treatment, $(52.1 \%)$ said yes, while the rest (47.9\%) said no.

Table 2. Distribution of volunteers according to relation between different types of prostheses and factors affecting on treatment choices.

\begin{tabular}{|c|c|c|c|c|c|c|c|c|}
\hline \multirow[t]{2}{*}{ Variables } & \multicolumn{2}{|c|}{ Fixed prostheses } & \multicolumn{2}{|c|}{ Removable prostheses } & \multicolumn{2}{|c|}{ Implant } & \multicolumn{2}{|c|}{ Total } \\
\hline & $(\mathrm{N})$ & $(\%)$ & $(\mathrm{N})$ & $(\%)$ & $(\mathrm{N})$ & $(\%)$ & $(\mathrm{N})$ & $(\%)$ \\
\hline Cost & 45 & $70.3 \%$ & 8 & $12.5 \%$ & 11 & $17.2 \%$ & 64 & $100 \%$ \\
\hline Pain & 17 & $94.4 \%$ & 0 & $0.0 \%$ & 1 & $5.6 \%$ & 18 & $100 \%$ \\
\hline Surgery & 5 & $62.5 \%$ & 1 & $12.5 \%$ & 2 & $25.0 \%$ & 8 & $100 \%$ \\
\hline Phobia & 12 & $60.0 \%$ & 3 & $15.0 \%$ & 5 & $25.0 \%$ & 20 & $100 \%$ \\
\hline Time and duration & 23 & $71.9 \%$ & 3 & $9.4 \%$ & 6 & $18.8 \%$ & 32 & $100 \%$ \\
\hline
\end{tabular}




\section{Discussion}

This study aimed to correlate between socioeconomic status of Saudi Arabian volunteers and different treatment modalities for the replacement of missing teeth. On one hand, gender was found to be a patient factor that might influence treatment options. It was found that when females chose to replace the missing tooth, they usually favor fixed or implant treatment option more than removable treatment modality and this could be due to the fact that females are more apprehensive about their appearance and removable prosthesis makes them more conscious.

Most of the patients belonged to the twenty-five to fifty years' age. There were fewer patients more than fifty years old because geriatric patients give a lower priority to dental health [15].

On the other hand, level of education played role in the choice whether to seek treatment or not. $83.8 \%$ of the subjects who were in more than high school education. That means the level of education could affect the patient's awareness regarding the importance of tooth replacement.

The majority of the patients in our study gave economic reasons for not replacing teeth. Cost was the main barrier for obtaining dentures and is in agreement with the findings of Macek et al. [16].

When patients where asked about factors affecting their choice of treatment modality overall, cost was the highest reported factor (45.1\%) followed by duration of treatment $(22.5 \%)$, then phobia and pain (14.1\%), (12.7\%), respectively of no surprise, $60 \%$ of patients with higher income chose the implant treatment option. Therefore, persons of low socioeconomic status tend to seek low cost treatment.

Accordingly, a study by Tepper et al. [19] reported that the cost was one of the most important factors for choosing dental replacement especially for implant treatment option.

Hastreiter and Jiang [18] who reported that dental implants can provide various clinical and quality of life advantage compared to FPD and RPD, but it is more expensive than other principal single-tooth replacement alternatives

A common idea in restorative dentistry is to use a fixed prosthesis whenever possible. Rarely does a patient desire or accept a removable partial prosthesis as a substitute for a single missing tooth especially anterior tooth [20]. The usual indication for the removable option is economics. In this study only $9.7 \%$ of subjects preferred RPD because they are less costly than other treatment option which means that most of the subjects from RPD group in this study reported that they were not affected by cost. Hebel et al. [11] who reported in their study that one of the FPD advantages is that, it is completed in relatively short time, making duration of FPD treatment a deciding factor which is in agreement with what is found in our study. Kvale et al. [21] did a metaanalytic and systematic quantitative approach to examine the effects of behavioral interventions for dental phobia.

From all treatment modalities RPD had the highest rate of dissatisfaction $(26 \%)$ when compared with others. Dissatisfaction was related to mastication, esthetics, number of missing teeth and maintenance of oral hygiene.

Patients as well as dentists' preferences regarding treatment options depend on several factors such as rejection to surgical procedures, treatment duration, cost, pain or dental phobia. For a true economic evaluation, cost and benefits of different therapies are usually compared.
Additional research is needed to assess lifetime costs that include initial and maintenance costs, and future replacement costs associated with various alternatives. Besides, most of the reported studies compared FPD cost with other modalities. A multivariate analysis by Arnbjerg et al. [22] reported that satisfaction with previous dental care depends primarily on three factors; treatment by the dentist of choice, chewing ability and satisfaction with their own dental conditions. Our result showed that most of the subjects reported that missing tooth should be replaced for both esthetic and functional reasons.

Osterberg et al. reported that esthetic rather than functional factors determined an individual's subjective need for the replacement of missing teeth [17].

Future studies should determine how the dental profession and society might address an increased demand for services among people who have limited financial resources. These studies would provide important insights into the various types of assistance and insurance programs that might be designed and implemented to benefit older adults [16].

As in any study, this investigation has its limitations many factors must be considered when choosing between different treatment options for the replacement of a missing teeth, often the bias of the dentist plays a role rather than objective appraisal of the treatment options. Patient awareness of the advantages and disadvantages of different treatment modalities is very important for decision making, therefore there are many factors make the teeth replacement one of the most challenging restorations in dentistry. As a result, for years patients were advised to place their desires aside and accept the limitations of a fixed partial denture. However, in light of the present technology, the major reasons for suggesting the fixed partial denture are its clinical ease and reduced time and cost.

\section{Conclusion}

Within limitation of this study it was conclude that:

- Regarding the socioeconomic status of patients in relation to different types of prosthetic treatment it was found that the level of education and monthly income have affected significantly the treatment choice.

- Among the multiple factors affecting patient's decision to the final treatment modality for replacement of missing teeth, duration of treatment and cost were most important factors.

- The highest satisfaction with aesthetic and function was in the implant group and the least in RPD group. Problems with speech only with RPD treatment.

\section{References}

1. Ozakar-Ilday N, Zorba YO, Yildiz M, Erdem V, Seven N, et al. (2013) Three-year clinical performance of two indirect composite inlays compared to direct composite restorations. Med Oral Patol Oral Cir Bucal 18: e521-528. [Crossref]

2. Soares CJ, Celiberto L, Dechichi P, Fonseca RB, Martins LR (2005) Marginal integrity and microleakage of direct and indirect composite inlays: SEM and stereomicroscopic evaluation. Braz Oral Res 19: 295-301. [Crossref]

3. Syrek A, Reich G, Ranftl D, Klein C, Cerny B, et al. (2010) Clinical evaluation of allceramic crowns fabricated from intraoral digital impressions based on the principle of active wavefront sampling. $J$ Dent 38: 553-559. [Crossref]

4. Duquia Rde C, Osinaga PW, Demarco FF, de V Habekost L, Conceição EN (2006) Cervical microleakage in MOD restorations: in vitro comparison of indirect and direct composite. Oper Dent 31: 682-687. [Crossref]

5. Zarrati S, Mahboub F (2010) Marginal adaptation of indirect composite, glass-ceramic 
inlays and direct composite: an in vitro evaluation. J Dent (Tehran) 7: 77-83. [Crossref]

6. van der Meer WJ, Andriessen FS, Wismeijer D, Ren Y (2012) Application of intraoral dental scanners in the digital workflow of implantology. PLoS One 7: e43312. [Crossref]

7. Patzelt SB, Lamprinos C, Stampf S, Att W (2014) The time efficiency of intraoral scanners: an in vitro comparative study. J Am Dent Assoc 145: 542-551. [Crossref]

8. Lee SJ, Gallucci GO (2013) Digital vs. conventional implant impressions: efficiency outcomes. Clin Oral Implants Res 24: 111-115. [Crossref]

9. Almeida e Silva JS, Erdelt K, Edelhoff D, Araújo É, Stimmelmayr M, et al. (2014) Marginal and internal fit of four-unit zirconia fixed dental prostheses based on digital and conventional impression techniques. Clin Oral Investig 18: 515-523. [Crossref]
10. Ting-Shu S, Jian S (2015) Intraoral Digital Impression Technique: A Review. $J$ Prosthodont 24: 313-321. [Crossref]

11. Seelbach P, Brueckel C, Wöstmann B (2013) Accuracy of digital and conventional impression techniques and workflow. Clin Oral Investig 17: 1759-1764. [Crossref]

12. Zaruba M, Kasper R, Kazama R, Wegehaupt FJ, Ender A, et al. (2014) Margina adaptation of ceramic and composite inlays in minimally invasive mod cavities. Clin Oral Investig 18: 579-587. [Crossref]

13. Milleding P (1992) Microleakage of indirect composite inlays. An in vitro comparison with the direct technique. Acta Odontol Scand 50: 295-301. [Crossref]

14. Ng J, Ruse D, Wyatt C (2014) A comparison of the marginal fit of crowns fabricated with digital and conventional methods. J Prosthet Dent 112: 555-560. [Crossref]

Copyright: (C2016 Shafaei AA. This is an open-access article distributed under the terms of the Creative Commons Attribution License, which permits unrestricted use, distribution, and reproduction in any medium, provided the original author and source are credited. 